\title{
Current and Novel Treatment Strategies in Children with Congenital Adrenal Hyperplasia
}

\author{
Anna Nordenström ${ }^{\mathrm{a}}$ Henrik Falhammar ${ }^{\mathrm{b}}$ Svetlana Lajic $^{\mathrm{a}}$ \\ aPediatric Endocrinology Unit, Department of Women's and Children's Health, Karolinska Institutet, \\ Karolinska University Hospital, Stockholm, Sweden; bepartment of Molecular Medicine and Surgery, \\ Department of Endocrinology, Karolinska Institutet, Karolinska University Hospital, Stockholm, Sweden
}

\section{Keywords}

21-Hydroxylase deficiency - Cytochrome P450 family 21 subfamily A member 2 . Hydrocortisone replacement . Fludrocortisone - Modified release hydrocortisone - Growth . Puberty - Stress dosing · Adrenal crisis · Hypoglycemia . Neonatal screening $\cdot 17$-Hydroxyprogesterone . Nevanimibe - Corticotropin-releasing hormone-receptor antagonist

\footnotetext{
Abstract

Background: The standard treatment for congenital adrenal hyperplasia (CAH) in children is still hydrocortisone. Improved strategies for timing of the dose during the day and the dose per square meter body surface area used in children of different ages and developmental phases have improved the situation and outcome for the patients. Neonatal screening enables an earlier diagnosis and initiation of treatment, prevents from adrenal crisis, and improves growth and development also for children with the less severe forms of CAH. Summary: This review describes the current treatment strategies for children with CAH and discusses some potential treatment options that have been developed with the primary aim to decrease the adrenal androgen production. Novel modified re-
}

lease glucocorticoid therapies are also discussed. Key Messages: The long-term effects of the new adjunct therapies are unknown, and some are not suitable for use in children and adolescents. The effects of the new therapies on bone mineral density, gonadal functions, and long-term cognitive development are yet to be assessed. It is not known what levels of adrenal androgens are optimal for normal growth, puberty, and bone health. The basis of using glucocorticoids and mineralocorticoids in the treatment of $\mathrm{CAH}$ remains, and in some individuals, it may be beneficial to add therapies to reduce the androgen load during certain life stages.

C 2022 The Author(s).
Published by S. Karger AG, Basel

\section{Introduction}

Congenital adrenal hyperplasia (CAH) due to 21-hydroxylase deficiency (21OHD) is a relatively common autosomal recessive disorder treated and followed by pediatric endocrinologists in their daily practice [1,2].21OHD affects approximately 1:10,000-1:15,000 newborns [2-6]. Newborn screening programs are in place in more than 50 countries worldwide, enabling an early diagnosis in patients with classic $\mathrm{CAH}[5,7-10]$. (c) 2022 The Author(s).

Published by S. Karger AG, Basel

This is an Open Access article licensed under the Creative Commons Attribution-NonCommercial-4.0 International License (CC BY-NC) (http://www.karger.com/Services/OpenAccessLicense), applicable to the online version of the article only. Usage and distribution for commercial purposes requires written permission.
Correspondence to:

Svetlana Lajic, svetlana.lajic@ ki.se 
First-line standard treatment is still glucocorticoid replacement therapy with the addition of mineralocorticoids when required $[1,2]$. The current treatment strategy, which has limitations, can be challenging for both physicians and patients. The glucocorticoid dose often has to be supraphysiological to adequately suppress the hypothalamic-pituitary-adrenal axis with adverse longterm outcomes $[2,11]$.

This review aims to discuss current and novel treatment strategies in children with $\mathrm{CAH}$ that can potentially improve long-term outcomes.

\section{Early Diagnosis with Neonatal Screening}

The primary aim of neonatal screening for $\mathrm{CAH}$ is to avoid salt-losing crises and neonatal death. The detection rate for salt-wasting (SW) CAH is high, but the efficiency of the screening programs varies from $100 \%$ to less than $70 \%$ detection of SW cases [12-14]. The false-positive rate has been reduced by using gestational age- and birth weight-related cut-off levels for 17-hydroxyprogesterone (17-OHP), the biomarker analyzed in dried blood spots in the neonate, usually at day 2 after birth $[5,13,15]$. Overall, the positive predictive value for $21 \mathrm{OHD}$ screening for term babies is $\sim 2 \%-25 \%$ in different studies $[4,5$, 14-17]. A second-tier approach using tandem-mass spectrometry to identify multiple steroidogenic metabolites or quotes thereof can improve the positive predictive value to about $70 \%$ [18-23].

In addition to saving lives, neonatal screening improves growth and development in children with milder forms of $\mathrm{CAH}$ as early treatment prevents androgen excess during childhood $[7,13]$. Screening also has a positive impact on the cognitive development of the child, most likely because salt-losing crisis and hypoglycemia can be avoided in addition to preventing the use of high doses of glucocorticoids to treat an adrenal crisis [2426].

For screening to be effective, a good follow-up is an essential and immediate treatment if the 17-OHP is markedly elevated or if the child has clinical signs of adrenal crisis, failure to thrive, or virilization of the external genitalia. CYP21A2 genotyping should always be performed to confirm the diagnosis and guide treatment decisions. Because neonatal screening does not detect milder phenotypes of $21 \mathrm{OHD}$, pediatricians and other physicians caring for children must be aware that signs of androgen excess, including growth acceleration, can be a symptom of $\mathrm{CAH}$.

\section{Clinical Presentation of CAH}

When the child does not undergo neonatal screening, undiagnosed patients of both sexes with the salt-losing form of CAH will develop symptoms of failure to thrive within the first 2-3 weeks after birth [1]. Aldosterone deficiency causes hyponatremia, hyperkalemia, acidosis, and the development of salt crisis with circulatory collapse. The adrenal crisis, if left untreated, is lethal [27]. Females with classic $\mathrm{CAH}$ have prenatal virilization of the genitalia, which causes uncertainty of the sex assignment at birth. Boys may have hyperpigmented scrotum and a larger phallus.

During childhood, infections and stressful events can trigger overt cortisol and aldosterone deficiency in undiagnosed patients with simple virilizing $\mathrm{CAH}$. Even patients with the mildest form of CAH, the nonclassic (NC) form, may show signs of cortisol deficiency during severe infections or when subjected to anesthesia during a surgical procedure [28]. However, these milder cases typically come to diagnosis when they develop signs of androgen excess such as acne, pseudo pubertas praecox, and growth acceleration $[29,30]$. Typical symptoms in adolescents and adults are acne, hirsutism, menstrual disturbances, or infertility. In children with NC CAH, most of those diagnosed before age 10 years had premature pubarche as the primary symptom $[31,32]$.

\section{The Diagnostic Setup}

The diagnosis has to be investigated with suspicion of $\mathrm{CAH}$, either clinically or because of a positive screening result. Analysis of 17-OHP in plasma and adrenal hormone levels need to be performed, including testosterone and androstenedione, which all are elevated in SW CAH $[33,34]$. A karyotype may be indicated. In late diagnosed cases a Synachten ${ }^{\circledR} /$ cosyntropin $(0.25 \mathrm{mg}$ of ACTH1-24) stimulation test may be done with measurements of 17 OHP and cortisol levels, the latter to determine adrenal insufficiency [30]. The diagnostic cutoff for CAH is a basal or stimulated level of 17-OHP above $30 \mathrm{nmol} / \mathrm{L}$. A basal 17 -OHP level $>6$ but $<30 \mathrm{nmol} / \mathrm{L}$ and suspicion of CAH should lead to a stimulation test. In classic $\mathrm{CAH}$ the stimulated $17-\mathrm{OHP}$ is typically $>300 \mathrm{nmol} / \mathrm{L}[35,36]$.

The genotype and phenotype correlation for $21 \mathrm{OHD}$ is good and 10 common mutations, including deletion of the CYP21A2 gene (del/conversion, E3 $\triangle 8 \mathrm{bp}$, ClusterE6, Leu307fs, Q318X, R356W, I2splice, I172N, P30L, V281L, P453S), are responsible for more than $95 \%$ of all cases $[1$, 


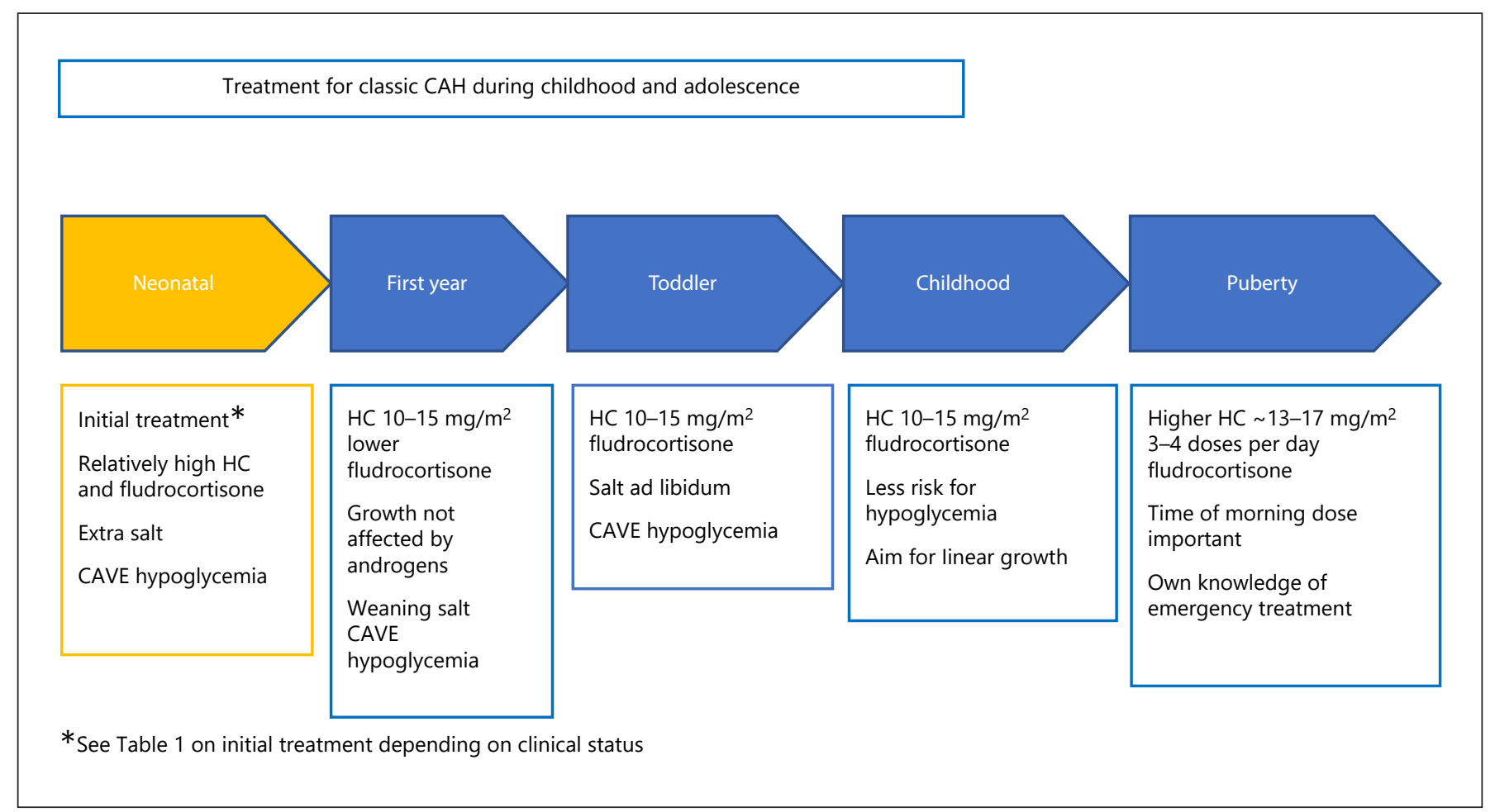

Fig. 1. Treatment for classic CAH during childhood and adolescence.

2]. Because genotyping helps in treatment decisions and diagnosis in unclear cases suspected of having $\mathrm{NC} \mathrm{CAH}$, we believe all cases should be genotyped. However, it is crucial to be mindful that not all children with NC CAH need to be treated as soon as diagnosed. This is because once a child is on continuous replacement therapy, the child will be at risk of adrenal crises if a stressful situation arises requiring an acute treatment regimen [28].

\section{Replacement Therapy}

For children with $\mathrm{CAH}$, treatment goals include achieving normal growth, normal bone maturation, and timing of puberty, as well as good cognitive development, self-esteem, and quality of life (QoL). In addition, treatment should prevent long-term sequelae such as cardiovascular complications, fractures, testicular adrenal rest tumors, infertility, and not least to avoid adrenal crisis and sudden death [2].

The general treatment strategy for classic CAH is glucocorticoid (hydrocortisone or in some countries cortisone acetate) and mineralocorticoid (9-alfa-fludrocortisone) replacement as well as optimal androgen control.
Mimicking the circadian rhythm by giving the highest dose of hydrocortisone in the morning is the preferred strategy, but the dose has to be individualized because of individual variations in uptake and the half-life of hydrocortisone $[33,37]$. Impaired ability to reactivate cortisone to cortisol (via 11betaHSD type 1) requires more frequent dosing in addition to a higher total dose [38]. In these cases, cortisone acetate cannot be used as substitution therapy. The treatment strategies outlined below vary contingent on the age of the child (for summary see Fig. 1).

\section{The Neonatal Period}

Hydrocortisone treatment is initiated at diagnosis (Table 1). The dose should be sufficient for replacement, but 17-OHP during the first year of life should not be suppressed completely but rather allowed to be increased enough to avoid overtreatment and adverse effects on growth.

In a severely ill newborn with hyponatremia and hyperkalemia prompt treatment with hydrocortisone intravenously (iv) (i.e., Solu-Cortef ${ }^{\circledR}$ ) is initiated at a dose of $5-10 \mathrm{mg} / \mathrm{kg}$ followed by infusion of hydrocortisone, $25 \mathrm{mg} / 24 \mathrm{~h}$. In addition, an intravenous glucose infusion 
Table 1. Treatment for classic $\mathrm{CAH}$ at diagnosis during the neonatal period

\begin{tabular}{ll}
\hline Severely ill newborn & Glucose $(50 \mathrm{mg} / \mathrm{mL})$ infusion iv including sodium chloride min. $80 \mathrm{mM} / \mathrm{L}$ \\
\hline Hyponatremia & Hydrocortisone infusion iv $25 \mathrm{mg} / 24 \mathrm{~h}$ \\
\hline Hyperkalemia & Glucose $(50 \mathrm{mg} / \mathrm{mL})$ infusion iv including sodium chloride $\mathrm{min} .80 \mathrm{mM} / \mathrm{L}$ \\
\hline Affected newborn but stable clinical & Hydrocortisone orally $20-30 \mathrm{mg} / \mathrm{m}^{2} / \mathrm{day}$, three divided doses \\
status & Fludrocortisone orally $50-100 \mu \mathrm{g} / \mathrm{day}$ \\
& Sodium chloride solution $2 \mathrm{mmol} / \mathrm{kg} / \mathrm{day}, 4-6$ divided doses \\
\hline No clinical symptoms & Hydrocortisone orally $10-15 \mathrm{mg} / \mathrm{m}^{2} /$ day, three divided doses \\
& Fludrocortisone orally $50-100 \mu \mathrm{g} /$ day \\
& Sodium chloride solution $2 \mathrm{mmol} / \mathrm{kg} /$ day, $4-6$ divided doses \\
\hline
\end{tabular}

(50 mg/mL) with sodium chloride (minimum $80 \mathrm{mM}$ sodium/L glucose) is started.

If the child is stable, hydrocortisone treatment at a dose of $20-30 \mathrm{mg} / \mathrm{m}^{2}$ per day is initiated orally, divided into three doses per day. Fludrocortisone is given at a dose of 50-100 $\mu \mathrm{g} /$ day. Adding a sodium chloride solution $(0.23 \mathrm{~g} / \mathrm{L}$, dose $2 \mathrm{~mL} / \mathrm{kg}$ a day, or $2 \mathrm{mmol} / \mathrm{kg}$ a day) is necessary for small children with SW CAH, at least during the first year of life because of renal immaturity and mineralocorticoid resistance $[1,39,40]$. In a child with no clinical symptoms replacement with hydrocortisone given orally at a dose of $10-15 \mathrm{mg} / \mathrm{m}^{2} /$ day is initiated together with mineralocorticoid and sodium chloride as described above $[1,40]$.

The 17-OHP screening level provides guidance in treatment decisions on the initial dose of glucocorticoids. High levels (above $200 \mathrm{nmol} / \mathrm{L}$ ) are indicative of classic SW CAH requiring a higher dosage (such as $2.5-5 \mathrm{mg} \times$ 3 of hydrocortisone) during the first week of life to suppress the overactivity of adrenal hyperplasia [41]. If the screening level of 17-OHP is exceptionally high, the treatment strategy for a severely ill child should be used (i.e., intravenous treatment). As for the glucocorticoid effect, $0.1 \mathrm{mg}$ of fludrocortisone corresponds to $1-1.5 \mathrm{mg}$ of hydrocortisone. In a neonate, this should be taken into account. Salt supplementation during the first year of life improves growth and results in a taller final height [42].

Dosage in young children is challenging in that many countries do not provide hydrocortisone in lower doses than 10-mg tablets. Therefore, compounded preparations either as capsules that can be opened and the powder dissolved in liquid or as an oral solution is prepared at local or more centralized pharmacies. However, the quality of the different batches of compounded hydrocortisone can vary [43]. Recently, an immediate release granule formulation, Alkindi ${ }^{\circledR}(0.5 \mathrm{mg}, 1 \mathrm{mg}, 2 \mathrm{mg}, 5 \mathrm{mg})$, with hydrocortisone coated with a taste-masking layer containing magnesium stearate [44-46] was approved for use in the European Union (2018) and the USA (2020). The granule facilitates the exact dosing in the capsules. The preparation with granules, however, may be an issue for the infant because of the large amounts of granules that cannot dissolve in liquid due to the magnesium stearate coating. Another aspect is the relatively high cost and that it is not approved for reimbursement within the national health services of all countries in Europe.

\section{Childhood}

To maintain a linear growth rate during childhood a dose of $10-12 \mathrm{mg} / \mathrm{m}^{2} /$ day of hydrocortisone is often required $[47,48]$. Inadequate treatment during the prepubertal years accelerates bone age and results in attenuated height gain during the pubertal growth spurt $[42,49]$ as well as a compromised final height.

After 2 years of age, the fludrocortisone dose is often $100 \mu \mathrm{g} / \mathrm{m}^{2} /$ day in SW CAH. In simple virilizing CAH, a small dose of mineralocorticoid replacement is beneficial, allowing for a lower total hydrocortisone dose [50].

Treatment efficacy is monitored by tracking the growth and signs of androgen excess such as adult body odor, oily skin, and hair or appearance of pubic hair. Accelerated bone age or pubic hair is not seen before the age of 1.5 years $[48,51]$. Twenty-four-hour profiles of $17-\mathrm{OHP}$ levels in blood samples collected on filter paper cards is another useful approach to monitor treatment efficacy and dose adjustments [52-54]. The mineralocorticoid effect is followed with measurements of renin to maintain the plasma renin just above the normal range; however, the dose is often relatively constant throughout the childhood $[40,50]$. Blood pressure should be measured at each outpatient visit. In addition, analysis of androgens (e.g., androstenedione and testosterone) is often used. New 
Table 2. Emergency regimen to prevent and treat adrenal crisis in children with CAH

A. In case of moderate physical stress

Fever between $38^{\circ} \mathrm{C}$ and $39^{\circ} \mathrm{C}$

Illness that requires bed rest

Infection that requires treatment with antibiotics

Minor surgical interventions in local anesthesia

Action: double the daily dose of hydrocortisone and divide the medication into four doses over $24 \mathrm{~h}$

Be aware that low body temperature $<36.5^{\circ} \mathrm{C}$ can signify hypoglycemia due to cortisol deficiency. Give at least a double dose of daily hydrocortisone and additional carbohydrates

B. In case of severe physical stress

Fever above $39^{\circ} \mathrm{C}$

Infection with vomiting, diarrhea, or both

Surgical interventions in local anesthesia such as dental interventions

Action: increase the daily dose of hydrocortisone at least threefold and divide the medication into four doses over $24 \mathrm{~h}$

In case of sustained vomiting or diarrhea go to the hospital!

C. In case of severe trauma or illness when oral medication cannot be administered or when the child becomes more ill regardless of the above-taken actions

Action: inject hydrocortisone (Solu-Cortef ${ }^{\circledR}$ ) intramuscularly (im)/or iv and GO TO THE HOSPITAL for further treatment

Dose of Solu-Cortef ${ }^{\circledR} 50 \mathrm{mg} / \mathrm{mL}$ :

\begin{tabular}{ll}
\hline Weight of the child (age of the child) & Solu-Cortef $50 \mathrm{mg} / \mathrm{mL}$ \\
\hline$<15 \mathrm{~kg}$ (0-2 years) & $25 \mathrm{mg}$ \\
$15-25 \mathrm{~kg}$ (2-6 years) & $50 \mathrm{mg}$ \\
$>25 \mathrm{~kg}$ (>6 years) & $100 \mathrm{mg}$ \\
\hline
\end{tabular}

biomarkers (e.g., 11-oxy-androgens) are potential novel markers for treatment follow-up [55-57]. However, it is not clear what levels of these hormones indicate adequate hormonal control [58].

\section{Adolescence}

During pubertal development, sex hormone and growth hormone/IGF-1 production are increased. At the same time, the activity of the 11 beta-hydroxysteroid dehydrogenase type 1 enzyme is reduced owing to inhibition by increased IGF-1 levels [59]. Thus, a need for higher doses and sometimes more frequent dosing of hydrocortisone during puberty is required. Doses above $17 \mathrm{mg} /$ $\mathrm{m}^{2} /$ day, however, should be avoided not to compromise growth $[47,60]$.

Extra dosing of hydrocortisone (usually $2.5 \mathrm{mg}$ ) may be required during sports with higher intensities since patients with CAH have reduced catecholamine production and aberrant glycemic control [61-63]. From late childhood and early adolescence, it may become more difficult to suppress the morning increase in 17-OHP. This rise in 17-OHP can be overcome by taking the first dose earlier in the morning. The increased clearance of cortisol during puberty may require a switch to a four-dose regimen in addition to increased dosing.

Treatment in Congenital Adrenal Hyperplasia

\section{Emergency Regimen}

During acute illness or significant physical stress (e.g., surgical interventions), the dose of hydrocortisone must be sufficiently increased. The daily dose should be doubled if the child has a fever above $38^{\circ} \mathrm{C}$ and tripled above $39^{\circ} \mathrm{C}$, with the dose spread more evenly over the $24 \mathrm{~h}$ (Table 2). In case of vomiting or severe diarrhea, intravenous or intramuscular injections of hydrocortisone should be given [27]. Hospital admission and treatment with intravenous glucose and sodium chloride may be required.

Parents and children must be repeatedly informed and given written information about the stress dosing regimen and in which situations they should seek medical attention. The patient should have an emergency kit with a supply of injectable hydrocortisone and carry medical information (e.g., medical identification jewelry and information on dosing on a steroid emergency card) $[41,64$, 65]. The family must always seek medical care at the nearest hospital if and when the child has received intramuscular hydrocortisone.

In preparation for surgery (day 1) 25-100 mg of hydrocortisone is given iv depending on the size/age of the child $1 \mathrm{~h}$ before the start of the procedure, followed by an iv infusion of $2-3 \mathrm{mg} / \mathrm{m}^{2}$ of hydrocortisone per hour during the procedure (equals $50-75-100 \mathrm{mg} / \mathrm{m}^{2} / 24 \mathrm{~h}$ de- 
pending upon the size of the child). The hydrocortisone can be diluted in $50-1,000 \mathrm{~mL}$ glucose $(50 \mathrm{mg} / \mathrm{mL})$ with $80 \mathrm{mmol}$ sodium per liter of glucose. During day 2, hydrocortisone is given either iv or orally in a dose of $40 \mathrm{mg} /$ $\mathrm{m}^{2} / 24 \mathrm{~h}$ divided into four doses; on day 3 , hydrocortisone iv or orally $30 \mathrm{mg} / \mathrm{m}^{2} / 24 \mathrm{~h}$ divided into four doses is administered. Next, and depending on clinical status, usual replacement therapy or a double dose is recommended. Mineralocorticoid replacement is omitted on the day of surgery and as long as hydrocortisone is given iv in high doses. Mineralocorticoid replacement is recommenced at the usual maintenance dose when the patient transitions to oral therapy.

Patients with $\mathrm{CAH}$ have a compromised epinephrine production that puts them at an increased risk of hypoglycemia during acute illness [66-68]. Hypoglycemia may not only occur during infections but also when the glucocorticoid dose is tapered too quickly after a more extended period of illness with high fever or vomiting [69]. Due to the lack of epinephrine, the child does not show the signs usually seen during an episode of hypoglycemia (e.g., pallor and tremor). Thus, it is of utmost importance to inform the family about the preventive measures that should be taken if illness and febrile episodes occur. In addition to the glucocorticoid regimen, extra carbohydrates are important, especially in the young child $[68,69]$.

\section{Bilateral Adrenalectomy}

Bilateral adrenalectomy, although drastic, can be used to control adrenal androgens and 17-OHP levels in CAH. A meta-analysis of 48 published cases (4 months-56 years) showed $71 \%$ of patients had symptomatic improvement postoperatively, with $10 \%$ reporting shortand $27 \%$ long-term adverse outcomes [70]. The risk of adrenal crisis was much higher (14.8 per 100 patientyears) than previously reported for CAH (5.8 per 100 patient-years) [71]. Because of the risk of long-term adverse outcomes, bilateral adrenalectomy is no longer recommended for $\mathrm{CAH}[1]$.

\section{Novel Therapeutic Strategies}

Glucocorticoid replacement therapy for $\mathrm{CAH}$ and other forms of primary adrenal insufficiency (PAI) has remained the same for decades. Optimizing the dosage and timing of the dose on the individual level has been emphasized. The normal cortisol production rate has a high intra- and interperson variability, with children and women showing lower cortisol production rates $(5-6 \mathrm{mg}$ / $\mathrm{m}^{2} /$ day) compared to a general mean of $7 \mathrm{mg} / \mathrm{m}^{2} /$ day (range $5-11 \mathrm{mg} / \mathrm{m}^{2} /$ day) [72-76]. The elderly has lower peaks and higher nadir values than children and adolescents $[72,73]$. A mean cortisol production rate of 5-11 $\mathrm{mg} / \mathrm{m}^{2} /$ day is equivalent to a $7.5-15 \mathrm{mg} / \mathrm{m}^{2} /$ day hydrocortisone dose. While being lifesaving for patients, the current treatment regimen fails to mimic the ultradian and circadian rhythm of cortisol secretion [77]. In addition, because cortisol levels are not coupled to the sleep rhythm in patients, the unnatural glucocorticoid fluctuations may disrupt the sleep cycle and contribute to adverse health outcomes $[77,78]$. Novel therapeutic strategies are justified to reduce or eliminate the long-term complications of over- and underdosing of glucocorticoids. Long-term complications in CAH include short final height [79], cardiometabolic complications [80, 81], low bone mineral density (BMD) and fractures [82-84], adrenal tumors [85], testicular tumors and fertility problems [86, 87], reduced working memory capacity $[25,26]$, altered gray matter brain structures and white matter microstructure [88-90], low QoL [91, 92], and death [93].

The treatment strategy for CAH is based on two approaches. Besides glucocorticoid and mineralocorticoid replacement, the effects of androgen excess have to be considered, especially in women. Other antiandrogenic drugs are needed in the treatment arsenal in addition to the possibilities we have today with the use of oral contraceptive pills and cyproterone acetate in adolescent and adult females. For children, the use of classic long-acting glucocorticoids (e.g., prednisolone/prednisone or dexamethasone) is not a therapeutic option. A study by Bonfig et al. [94] on 125 children with CAH treated with prednisone until final height was reached showed a reduced final height (-1SDS) compared to a target height. The hydrocortisone dose at the start of puberty was negatively correlated with final height. In addition, a dose of more than $20 \mathrm{mg} / \mathrm{m}^{2} /$ day in infants and above $15-17 \mathrm{mg} / \mathrm{m}^{2} /$ day in adolescents led to a shorter final height [94].

A few studies on children with CAH treated with dexamethasone have been reported [95-97]. Low-dose dexamethasone $\left(0.1 \mathrm{mg} / \mathrm{m}^{2} /\right.$ day; $8-10 \mathrm{mg} / \mathrm{m}^{2} /$ day hydrocortisone equivalents) given to eight infants from birth to 6.5 years showed no negative impact on growth or bone maturation [96]. However, the study period was short and the cohort small. Furthermore, no data on final height and no other outcome measures were analyzed, including metabolic profiles, bone mineralization, ambulatory $24-\mathrm{h}$ 
blood pressure, cognition, behavioral aspects, sleep, or QoL. Hydrocortisone and dexamethasone occupy mostly different receptors. Hydrocortisone also binds to the mineralocorticoid receptor, whereas dexamethasone binds only to the glucocorticoid receptor, implying that long-term outcome depends not only on the dose alone but also on the action of the different glucocorticoids on the receptor and cellular level.

A recent meta-analysis of patients with $\mathrm{CAH}$ using different glucocorticoid regimens showed that dexamethasone suppressed androstenedione and 17-OHP levels more than hydrocortisone. Moreover, dexamethasone increased body mass index (BMI) and decreased BMD more than hydrocortisone [98]. Prednisolone was in between hydrocortisone and dexamethasone in all measured variables. However, because the studies were not randomized trials, the results should be treated with caution.

Recently, slow- and modified-release hydrocortisone (MRHC) formulas have been developed in which patients take their medication only once or twice a day [99-101]. In addition to preventing sharp peaks and troughs in cortisol levels, the slow-release formula further ameliorates diurnal rhythmicity.

\section{Modified Release Glucocorticoids}

Plenadren ${ }^{\circledR}$ is a MRHC consisting of an outer coating that offers an immediate release of hydrocortisone and an inner core that provides extended release. The tablet was developed for patients with autoimmune Addison's disease and recommended to be taken once a day in the morning. Consequently, it is not suitable for patients with $\mathrm{CAH}$ as it does not suppress the morning rise in 17-OHP levels. Furthermore, a once-daily approach will not provide adequate control of androgen levels. Compared to immediate release hydrocortisone, it has a similar Cmax but a $20 \%$ reduced bioavailability and cannot reproduce the overnight cortisol rise [102].

Studies have been reported for patients with PAI caused by autoimmune Addison's disease or secondary adrenal insufficiency. In adults with PAI/secondary adrenal insufficiency Plenadren ${ }^{\circledR}$ treatment has been shown to improve BMI, blood pressure, metabolic profiles, QoL, and immunity [103-105]. It also restored the regulation of clock genes in immune cells compared to conventional hydrocortisone treatment [106]. Finally, it reduced the risk of adrenal crisis in a phase $3 \mathrm{~b}$ extension study [107]. Recently, effects on cognitive function, QoL, sleep quality, and prevalence of depression were evaluated [108]. Patients on MRHC ( $n=18 ; 10$ with PAI), compared to those

Treatment in Congenital Adrenal

Hyperplasia on conventional hydrocortisone treatment $(n=18 ; 10$ with PAI), tended to have better executive functioning ( $p$ $=0.099$ ), but an overall improvement in cognitive functions could not be demonstrated. Those on a higher dose of MRHC had better sleep quality than patients on lower doses. Only 1 of 3 patients in the study was younger than 50 years; studies in younger patients may lead to different findings. A reduction in fatigue has also been shown but the interindividual variation was high [109].

In a small observational study eight children (5 males, mean age 11 years) with PAI and symptoms of low cortisol concentrations during the day despite optimization of the conventional hydrocortisone treatment were offered treatment with Plenadren ${ }^{\circledR}$ in a twice-daily regimen [110]. Similar to studies of adults, MRHC treatment gave a smoother cortisol profile and sustained cortisol exposure. Long-term assessment of beneficial health effects in children is lacking, however. In an open, prospective trial 30 adult patients with different types of adrenal insufficiency (CAH $n=6)$ that were switched to MRHC from conventional glucocorticoids showed lower BMI and HbAlc during follow-up (median 202 days) [103]. The use of Plenadren ${ }^{\circledR}$ in children with $\mathrm{CAH}$ has not been evaluated and the drug is not licensed for use in children.

Chronocort ${ }^{\circledR} / \mathrm{Efmody}^{\circledR}$ is an MRHC preparation with a delayed and sustained action that can mimic the morning rise in cortisol secretion in adults $[99,102,111]$. In patients with PAI, it is taken in the evening. It suppresses the morning rise in 17-OHP and androstenedione (A4) in patients with $\mathrm{CAH}$ [111] but must be taken twice daily with two-thirds of the dose in the evening before bedtime and one-third in the morning upon awakening.

The phase 2 study on this particular MRHC (twice daily) included 16 adults ( 8 females, median age 24 years) with $\mathrm{CAH}$. The study objectives were to characterize the pharmacokinetic properties of the drug and disease control (analysis of androstenedione and 17-OHP) after 6 months of use with dose titration [112]. Before switching to treatment with Chronocort ${ }^{\circledR}$, patients were on hydrocortisone $(n=3)$, dexamethasone $(n=5)$, or prednisone $(n=7)$. The MRHC cortisol profiles were comparable to physiologic cortisol secretion, and after 6 months of treatment, the dose of hydrocortisone equivalents was lower when MRHC (25.9 mg/day) was used compared to conventional therapy $(28 \mathrm{mg} /$ day). MRHC also reduced the androstenedione area under the curve and the 24-h and morning 17-OHP area under the curve. Moreover, 59\% of the patients had 17-OHP values in the normal range. In females, there was an increase in lean mass and a decrease in BMD (possibly due to lower androgens). In con- 
trast, males showed a decrease in fat mass. No significant changes were noted for QoL or fatigue, although the follow-up time was short (6 months). Several patients experienced sleep disturbances while receiving MRHC; however, reducing the dose helped reduce early awakening.

Jones et al. [113] investigated the classic and alternative pathway-mediated androgen synthesis in $\mathrm{CAH}$ when Chronocort ${ }^{\circledR}$ (6 months) was used versus hydrocortisone in the same cohort of 16 patients. Patients on conventional treatment with hydrocortisone showed low excretion of classic pathway androgen metabolites but excess excretion of alternative pathway metabolites. MRHC treatment reduced 17-OHP and alternative pathway metabolites to near-normal levels. The early morning surge in the activation of both androgen pathway syntheses was diminished following MRHC therapy.

The randomized phase 3 trial on Chronocort ${ }^{\circledR}$ was performed in 122 adult patients with CAH [101]. The primary outcome was a change in 24-h SDS for 17-OHP (at 6 months) and efficacy, safety, and tolerability of Chronocort ${ }^{\circledR}$ for the extension study (18 months). The study did not reach its primary endpoint at 6 months but there was an effect on the 17-OHP levels at 1 and 3 months, as well as during morning hours (07.00-15.00) at 6 months. All patients, regardless of treatment, had lower morning levels (09.00) of 17-OHP, showing the positive effect of being included in a study with regular check-ups. The dose of MRHC was lowered in the extension study due to signs of overdosing during the first 6 months of treatment. The MRHC restored menstrual cycles in 8 patients and 7 pregnancies occurred (3 patients and 4 partners).

MRHC has the potential to improve metabolic control in adult patients with $\mathrm{CAH}$ but caution should be taken not to suppress the diurnal variation in 17-OHP completely and androgen levels as that could reflect a situation with overdosing. Long-term follow-up of the metabolic profiles, 24-h blood pressure, and cognitive outcome are areas still to be addressed.

Studies on Chronocort ${ }^{\circledR}$ in pediatric patients are lacking. However, there is a possibility that MRHC treatment could be useful for pediatric and adolescent patients, especially if the problem is excess androgen levels. Care should be exercised to keep the dose as low as possible to avoid a negative impact on growth, final height, and BMD.

In adults with $\mathrm{CAH}$, hydrocortisone administered subcutaneously via pump has been performed with improved adrenal steroid control and positive effects on health-related QoL [114]. It has also been trialed in an occasional child. However, because of practical difficul- ties and risks, pump treatment should be reserved only for children especially complicated to treat $[115,116]$.

\section{Nevanimibe}

Nevanimibe hydrochloride (ATR-101) is a selective acyl-coenzymeA:cholesterol O-acyltransferase 1 (ACAT1) inhibitor. ACAT1 is an ER enzyme that transfers a fatty acyl group from acyl-CoA to the $3 \beta$-hydroxyl moiety of cholesterol forming cholesteryl esters [117]. The drug is administered orally and, at lower doses, can reduce adrenal steroidogenesis across all pathways by decreasing the cholesteryl reservoir. Higher doses have been shown to increase the levels of free cholesterol in an adrenocortical cell line and the adrenal cortex of dogs, leading to cellular apoptosis [118].

Its potential in the treatment of $\mathrm{CAH}$ was tested in a multicenter, single-blind, dose-titration study in 10 adult patients in conventional $\mathrm{CAH}$ replacement therapy (mean age 30.3 years; hydrocortisone eq dose, mean 24.7 mg) [119]. Theoretically, androgen production could be diminished without increasing glucocorticoids. The goal was to reduce 17-OHP levels to twice below the upper reference level. This level, though, was only reached by 2 patients. Five more patients reduced the 17-OHP levels by $27 \%-72 \%$. Androstenedione levels were decreased only with the two highest dose titrations of nevanimibe (750-1,000 mg bid). No effects were seen for other parameters (e.g., free testosterone, DHEAS, renin, 11DOC, aldosterone, progesterone, cortisol, or ACTH).

The potential of this add-on therapy for androgen control in children and adolescents with $\mathrm{CAH}$ needs to be studied. However, the concern of such a study is that nevanimibe induces cell apoptosis and the effects this may have on the self-renewal of the adrenal cortex in a growing individual. Of note, the dose used to induce cell apoptosis in adrenocortical carcinomas is much higher than the doses used in the study described above. After an interim data review, the dose titration study (NCT03669549) with 500-2,000 mg nevanimibe bid for 16 weeks has been discontinued (https://clinicaltrials.gov/ct2/show/results/ NCT03669549).

\section{Abiraterone Acetate}

Another drug developed to reduce the androgen load is the CYP17A1 inhibitor abiraterone. It is used mainly to suppress androgen production in prostate cancer treatment. In the context of $\mathrm{CAH}$, it has been tested as an adjunct to glucocorticoid and fludrocortisone treatment to decrease the androgen excess in women with CAH. Six women with androstenedione above $12 \mathrm{nmol} / \mathrm{L}$ were in- 
cluded in a phase 1 study ( 6 days of treatment, 100-250 $\mathrm{mg}$ abiraterone acetate/ $\mathrm{d}$ in addition to gluco- and mineralocorticoid therapy). The authors reported reduced levels of androgens, including 11-oxoandrogens [120, 121].

The drug may also be beneficial in prepubertal children with classic CAH. To study the beneficial effects of abiraterone a phase 1 study has been registered (NCT02574910) and is estimated to be completed in January 2022 (https://clinicaltrials.gov/ct2/show/ NCT02574910). In pubertal girls, the drug would need to be supplemented with estrogen therapy due to inhibiting ovarian 17-hydroxylase activity. A possible advantage of abiraterone is counteracted in NC CAH because inhibition of CYP17A1 increases the synthesis of 11DOC, which may lead to hypokalemia and hypertension if not combined with hydrocortisone therapy.

\section{Corticotropin-Releasing Hormone-Receptor Antagonists}

Another approach to reducing the ACTH-driven androgen excess in $\mathrm{CAH}$ is to lower ACTH levels. Lowering the ACTH levels has been achieved with the corticotrophin-releasing factor (CRF) receptor-1 antagonist NBI77860 [122]. Eight women (18-58 years) with classic CAH were treated with dose escalation (placebo-300-600 $\mathrm{mg}$ at 22.00) of NBI77860 in a single-dose regimen, withdrawal of glucocorticoid therapy for $20 \mathrm{~h}$, and with 3 weeks of a washout period between each dose escalation. The highest dose of NBI77860 reduced the morning rise in ACTH and 17-OHP by $41 \%$ and $27 \%$, respectively.

Two-phase 2 open-label studies with the CRF1 receptor antagonist tildacerfont have recently been published [123]. In one of the studies, 11 patients (19-67 years, 55\% female) with androstenedione above twice the normal upper limit had an ACTH level reduction between 59.4\% and $28.4 \%, 17-\mathrm{OHP}$ reduction between $38.3 \%$ and $0.3 \%$ and reduction in androstenedione levels between 24.2\% and $18.1 \%$, with no clear dose-response of the different doses. In the second study, 5 patients with androstenedione two times above the normal baseline upper limit (2663 years, $40 \%$ female) had about an $80 \%$ reduction in ACTH, 17-OHP, and androstenedione levels. Two phase 3 studies are currently recruiting adults with $\mathrm{CAH}$ (https://clinicaltrials.gov/ct2/show/NCT04544410 and NCT04457336).

A phase 3 study to evaluate the efficacy, safety, and tolerability of the CRF1 receptor antagonist crinecerfont versus placebo in children with classic $\mathrm{CAH}$ was launched in June 2021 (https://clinicaltrials.gov/ct2/show/
NCT04806451). The study consists of a 28-week doubleblind, placebo-controlled period, followed by 24 weeks of treatment with crinecerfont. The duration of participation is approximately 14 months. A phase 3 study with crinecerfont treatment in adults with $\mathrm{CAH}$ is also underway (https://clinicaltrials.gov/ct2/show/NCT04490915).

\section{Conclusion}

Improved strategies for timing and administration of hydrocortisone have led to better health outcomes in patients with $\mathrm{CAH}$ identified through neonatal screening. An essential, though missing factor, is the lack of optimal biochemical parameters for follow-up. The recent description of increased levels of 11-keto testosterone and 11-keto DHT in CAH makes them candidates as markers for hormonal control. These novel markers may help solve the question of how the doses should be distributed throughout the day.

The long-term effects of the new therapeutic strategies are unknown and some are not suitable for use in children and adolescents. Moreover, the effects on BMD, gonadal functions, and cognitive outcome have yet to be assessed. Finally, it is unknown what levels of adrenal androgens are optimal for developing normal growth, puberty, and bone health. The basic therapeutic strategy of using glucocorticoids and mineralocorticoids in the treatment of $\mathrm{CAH}$ remains. In some individuals, it may be beneficial to add therapies to reduce the androgen load during certain life stages.

\section{Conflict of Interest Statement}

The authors have nothing to disclose.

\section{Funding Sources}

Svetlana Lajic was supported by Region Stockholm (clinical research appointment, DNR RS 2019-1140 and research grant DNR RS2020-0731), The Swedish Research Council (DNR 2021-02440) and Stiftelsen Frimurare Barnhuset.

\section{Author Contributions}

Svetlana Lajic wrote the first draft of the manuscript. All authors contributed to the final version of the manuscript. 


\section{References}

1 Speiser PW, Arlt W, Auchus RJ, Baskin LS, Conway GS, Merke DP, et al. Congenital adrenal hyperplasia due to steroid 21-hydroxylase deficiency: an endocrine society clinical practice guideline. J Clin Endocrinol Metab. 2018;103(11):4043-88.

2 Claahsen-van der Grinten HL, Speiser PW, Ahmed SF, Arlt W, Auchus RJ, Falhammar H, et al. Congenital adrenal hyperplasia: current insights in pathophysiology, diagnostics and management. Endocr Rev. 2022;43(1):91159.

3 Wedell A, Ritzén EM, Haglund-Stengler B, Luthman H. Steroid 21-hydroxylase deficiency: three additional mutated alleles and establishment of phenotype-genotype relationships of common mutations. Proc Natl Acad Sci U S A. 1992;89:7232-6.

4 Gidlof S, Falhammar H, Thilen A, von Dobeln U, Ritzen M, Wedell A, et al. One hundred years of congenital adrenal hyperplasia in Sweden: a retrospective, population-based cohort study. Lancet Diabetes Endocrinol. 2013;1(1):35-42.

5 Zetterstrom RH, Karlsson L, Falhammar H, Lajic S, Nordenstrom A. Update on the Swedish newborn screening for congenital adrenal hyperplasia due to 21-hydroxylase deficiency. Int J Neonatal Screen. 2020;6(3):71.

6 Krone N, Arlt W. Genetics of congenital adrenal hyperplasia. Best Pract Res Clin Endocrinol Metab. 2009;23(2):181-92.

7 White PC. Neonatal screening for congenital adrenal hyperplasia. Nat Rev Endocrinol. 2009;5(9):490-8.

8 Thilén A, Nordenström A, Hagenfeldt L, von Döbeln U, Guthenberg C, Larsson A. Benefits of neonatal screening for congenital adrenal hyperplasia (21-hydroxylase deficiency) in Sweden. Pediatrics. 1998;101:4-11.

9 Balsamo A, Cacciari E, Piazzi S, Cassio A, Bozza D, Pirazzoli P, et al. Congenital adrenal hyperplasia: neonatal mass screening compared with clinical diagnosis only in the Emilia-Romagna region of Italy, 1980-1995. Pediatrics. 1996;98:362-7.

10 Speiser PW, Chawla R, Chen M, Diaz-Thomas A, Finlayson C, Rutter MM, et al. Newborn screening protocols and positive predictive value for congenital adrenal hyperplasia vary across the United States. Int J Neonatal Screen. 2020;6(2):37.

11 Nordenstrom A, Lajic S, Falhammar H. Clinical outcomes in 21-hydroxylase deficiency. Curr Opin Endocrinol Diabetes Obes. 2021; 28(3):318-24

12 Sarafoglou K, Banks K, Gaviglio A, Hietala A, McCann M, Thomas W. Comparison of onetier and two-tier newborn screening metrics for congenital adrenal hyperplasia. Pediatrics. 2012;130(5):e1261-8.

13 Gidlof S, Wedell A, Guthenberg C, von Dobeln U, Nordenstrom A. Nationwide neonatal screening for congenital adrenal hyperplasia in Sweden: a 26-year longitudinal prospective population-based study. JAMA Pediatr. 2014; 168(6):567-74.

14 Coulm B, Coste J, Tardy V, Ecosse E, Roussey M, Morel Y, et al. Efficiency of neonatal screening for congenital adrenal hyperplasia due to 21-hydroxylase deficiency in children born in mainland France between 1996 and 2003. Arch Pediatr Adolesc Med. 2012;166(2): 113-20.

15 Pode-Shakked N, Blau A, Pode-Shakked B, Tiosano D, Weintrob N, Eyal O, et al. Combined gestational age- and birth weight-adjusted cutoffs for newborn screening of congenital adrenal hyperplasia. J Clin Endocrinol Metab. 2019;104(8):3172-80.

16 David J, Chrastina P, Peskova K, Kozich V, Friedecky D, Adam T, et al. Epidemiology of rare diseases detected by newborn screening in the Czech Republic. Cent Eur J Public Health. 2019;27(2):153-9.

17 Odenwald B, Dorr HG, Bonfig W, Schmidt H, Fingerhut R, Wildner M, et al. Classic congenital adrenal hyperplasia due to 21-hydroxylase-deficiency: 13 years of neonatal screening and follow-up in Bavaria. Klin Padiatr. 2015;227(5):278-83.

18 Minutti CZ, Lacey JM, Magera MJ, Hahn SH, McCann M, Schulze A, et al. Steroid profiling by tandem mass spectrometry improves the positive predictive value of newborn screening for congenital adrenal hyperplasia.[see comment]. J Clin Endocrinol Metab. 2004; 89(8):3687.

19 Janzen N, Sander S, Terhardt M, Steuerwald U, Peter M, Das AM, et al. Rapid steroid hormone quantification for congenital adrenal hyperplasia $(\mathrm{CAH})$ in dried blood spots using UPLC liquid chromatography-tandem mass spectrometry. Steroids. 2011;76(13):143742.

20 Lai F, Srinivasan S, Wiley V. Evaluation of a two-tier screening pathway for congenital adrenal hyperplasia in the New South Wales newborn screening programme. Int J Neonatal Screen. 2020;6(3):63.

21 Schwarz E, Liu A, Randall H, Haslip C, Keune F, Murray M, et al. Use of steroid profiling by UPLC-MS/MS as a second tier test in newborn screening for congenital adrenal hyperplasia: the Utah experience. Pediatr Res. 2009; 66(2):230-5.

22 Lasarev MR, Bialk ER, Allen DB, Held PK. Application of principal component analysis to newborn screening for congenital adrenal hyperplasia. J Clin Endocrinol Metab. 2020; 105(8):dgaa371.

23 Matern D, Tortorelli S, Oglesbee D, Gavrilov $D$, Rinaldo P. Reduction of the false-positive rate in newborn screening by implementation of MS/MS-based second-tier tests: the Mayo Clinic experience (2004-2007). J Inherit Metab Dis. 2007;30(4):585-92.

24 Messina V, Karlsson L, Hirvikoski T, Nordenström A, Lajic S. Cognitive function of children and adolescents with congenital adrenal hyperplasia: importance of early diagnosis. J Clin Endocrinol Metab. 2020;105(3):e68391.

25 Karlsson L, Gezelius A, Nordenstrom A, Hirvikoski T, Lajic S. Cognitive impairment in adolescents and adults with congenital adrenal hyperplasia. Clin Endocrinol. 2017; 87(6):651-9.

26 Browne WV, Hindmarsh PC, Pasterski V, Hughes IA, Acerini CL, Spencer D, et al. Working memory performance is reduced in children with congenital adrenal hyperplasia. Horm Behav. 2015;67:83-8.

27 Rushworth RL, Torpy DJ, Stratakis CA, Falhammar H. Adrenal crises in children: perspectives and research directions. Horm Res Paediatr. 2018;89(5):341-51.

28 Falhammar H, Nordenström A. Nonclassic congenital adrenal hyperplasia due to 21-hydroxylase deficiency: clinical presentation, diagnosis, treatment, and outcome. Endocrine. 2015;50(1):32-50.

29 Witchel SF, Azziz R. Nonclassic congenital adrenal hyperplasia. Int J Pediatr Endocrinol. 2010;2010:625105.

30 Nordenstrom A, Falhammar H. Management of endocrine disease: diagnosis and management of the patient with non-classic CAH due to 21-hydroxylase deficiency. Eur J Endocrinol. 2019;180(3):R127-45.

31 Moran C, Azziz R, Carmina E, Dewailly D, Fruzzetti F, Ibanez L, et al. 21-Hydroxylasedeficient nonclassic adrenal hyperplasia is a progressive disorder: a multicenter study. Am J Obstet Gynecol. 2000;183(6):1468-74.

32 Carmina E, Dewailly D, Escobar-Morreale HF, Kelestimur F, Moran C, Oberfield S, et al. Non-classic congenital adrenal hyperplasia due to 21-hydroxylase deficiency revisited: an update with a special focus on adolescent and adult women. Hum Reprod Update. 2017; 23(5):580-99.

33 Miller WL, Auchus RJ. The molecular biology, biochemistry, and physiology of human steroidogenesis and its disorders. Endocr Rev. 2011;32(1):81-151.

34 Kamrath C, Hartmann MF, Boettcher C, Zimmer KP, Wudy SA. Diagnosis of 21-hydroxylase deficiency by urinary metabolite ratios using gas chromatography-mass spectrometry analysis: reference values for neonates and infants. J Steroid Biochem Mol Biol. 2016;156:10-6.

35 Turcu AF, Auchus RJ. Adrenal steroidogenesis and congenital adrenal hyperplasia. Endocrinol Metab Clin North Am. 2015;44(2): 275-96.

36 Turcu AF, Rege J, Chomic R, Liu J, Nishimoto HK, Else T, et al. Profiles of 21-carbon steroids in 21-hydroxylase deficiency. J Clin Endocrinol Metab. 2015;100(6):2283-90.

37 Hindmarsh PC, Charmandari E. Variation in absorption and half-life of hydrocortisone influence plasma cortisol concentrations. Clin Endocrinol. 2015;82(4):557-61. 
38 Nordenstrom A, Marcus C, Axelson M, Wedell A, Ritzen EM. Failure of cortisone acetate treatment in congenital adrenal hyperplasia because of defective 11beta-hydroxysteroid dehydrogenase reductase activity. J Clin Endocrinol Metab. 1999;84(4):1210-3.

39 Mullis PE, Hindmarsh PC, Brook CG. Sodium chloride supplement at diagnosis and during infancy in children with salt-losing 21-hydroxylase deficiency. Eur J Pediatr. 1990;150(1):22-5.

40 Hindmarsh PC. Management of the child with congenital adrenal hyperplasia. Best Pract Res Clin Endocrinol Metab. 2009;23(2): 193-208.

41 Speiser PW, Azziz R, Baskin LS, Ghizzoni L, Hensle TW, Merke DP, et al. Congenital adrenal hyperplasia due to steroid 21-hydroxylase deficiency: an Endocrine Society clinical practice guideline. J Clin Endocrinol Metab. 2010;95(9):4133-60.

42 Van der Kamp HJ, Otten BJ, Buitenweg N, De Muinck Keizer-Schrama SMPF, Oostdijk W, Jansen $M$, et al. Longitudinal analysis of growth and puberty in 21-hydroxylase deficiency patients. Arch Dis Child. 2002 Aug; 87(2):139-44.

43 Neumann U, Burau D, Spielmann S, Whitaker MJ, Ross RJ, Kloft C, et al. Quality of compounded hydrocortisone capsules used in the treatment of children. Eur J Endocrinol. 2017; 177(2):239-42.

44 Whitaker MJ, Spielmann S, Digweed D, Hua$\tan \mathrm{H}$, Eckland D, Johnson TN, et al. Development and testing in healthy adults of oral hydrocortisone granules with taste masking for the treatment of neonates and infants with adrenal insufficiency. J Clin Endocrinol Metab. 2015;100(4):1681-8.

45 Neumann U, Whitaker MJ, Wiegand S, Krude $\mathrm{H}$, Porter J, Davies M, et al. Absorption and tolerability of taste-masked hydrocortisone granules in neonates, infants and children under 6 years of age with adrenal insufficiency. Clin Endocrinol. 2018;88(1):21-9.

46 Porter J, Withe M, Ross RJ. Immediate-release granule formulation of hydrocortisone, Alkindi(R), for treatment of paediatric adrenal insufficiency (Infacort development programme). Expert Rev Endocrinol Metab. 2018;13(3):119-24.

47 Bonfig W, Pozza SB, Schmidt H, Pagel P, Knorr D, Schwarz HP. Hydrocortisone dosing during puberty in patients with classical congenital adrenal hyperplasia: an evidencebased recommendation. J Clin Endocrinol Metab. 2009;94(10):3882-8.

48 Bonfig W. Growth and development in children with classic congenital adrenal hyperplasia. Curr Opin Endocrinol Diabetes Obes. 2017;24(1):39-42.

49 Balsamo A, Cicognani A, Baldazzi L, Barbaro $\mathrm{M}$, Baronio F, Gennari M, et al. CYP21 genotype, adult height, and pubertal development in 55 patients treated for 21-hydroxylase deficiency. J Clin Endocrinol Metab. 2003;88(12): 5680-8.
50 Witchel SF. Congenital adrenal hyperplasia. J Pediatr Adolesc Gynecol. 2017;30(5):520-34.

51 Thilén A, Woods KA, Perry LA, Savage MO, Wedell A, Ritzén EM. Early growth is not increased in untreated moderately severe 21-hydroxylase deficiency. Acta Paediatr. 1995;84:894-8.

52 Schwartz RP. Home monitoring of 17 hydroxyprogesterone levels: throw away the urine jug, mom, the filter paper just arrived. J Pediatr. 1999;134(2):140-2.

53 Bode HH, Rivkees SA, Cowley DM, Pardy K, Johnson S. Home monitoring of 17 hydroxyprogesterone levels in congenitx $127 \mathrm{drenal}$ hyperplasia with filter paper blood samples. J Pediatr. 1999;134(2):185-9.

54 Wieacker I, Peter M, Borucki K, Empting S, Roehl FW, Mohnike K. Therapy monitoring in congenital adrenal hyperplasia by dried blood samples. J Pediatr Endocrinol Metab. 2015;28(7-8):867-71.

55 Turcu AF, Auchus RJ. Novel treatment strategies in congenital adrenal hyperplasia. Curr Opin Endocrinol Diabetes Obes. 2016;23(3): 225-32.

56 Kamrath C, Wettstaedt L, Boettcher C, Hartmann MF, Wudy SA. Androgen excess is due to elevated 11-oxygenated androgens in treated children with congenital adrenal hyperplasia. J Steroid Biochem Mol Biol. 2018;178: 221-8.

57 Turcu AF, El-Maouche D, Zhao L, Nanba AT, Gaynor A, Veeraraghavan P, et al. Androgen excess and diagnostic steroid biomarkers for nonclassic 21-hydroxylase deficiency without cosyntropin stimulation. Eur J Endocrinol. 2020;183(1):63-71.

58 Kamrath C, Wettstaedt L, Boettcher C, Hartmann MF, Wudy SA. The urinary steroidome of treated children with classic 21-hydroxylase deficiency. J Steroid Biochem Mol Biol. 2017;165(Pt B):396-406.

59 Charmandari E, Hindmarsh PC, Johnston A, Brook CG. Congenital adrenal hyperplasia due to 21-hydroxylase deficiency: alterations in cortisol pharmacokinetics at puberty. J Clin Endocrinol Metab. 2001;86(6):2701-8.

60 Jääskelainen J, Voutilainen R. Growth of patients with 21-hydroxylase deficiency: an analysis of the factors influencing adult height. Pediatr Res. 1997;40:30-3.

61 Weise M, Drinkard B, Mehlinger SL, Holzer SM, Eisenhofer G, Charmandari E, et al. Stress dose of hydrocortisone is not beneficial in patients with classic congenital adrenal hyperplasia undergoing short-term, high-intensity exercise. J Clin Endocrinol Metab. 2004; 89(8):3679-84.

62 Weise M, Mehlinger SL, Drinkard B, Rawson E, Charmandari E, Hiroi M, et al. Patients with classic congenital adrenal hyperplasia have decreased epinephrine reserve and defective glucose elevation in response to highintensity exercise. J Clin Endocrinol Metab. 2004;89(2):591-7.

63 Bonnecaze AK, Reynolds P, Burns CA. Stressdosed glucocorticoids and mineralocorti- coids before intensive endurance exercise in primary adrenal insufficiency. Clin J Sport Med. 2019;29(6):e73-5.

64 Chrisp GL, Quartararo M, Torpy DJ, Falhammar H, Rushworth RL. Use of medical identification jewellery in children and young adults with adrenal insufficiency in Australia. Endocrine. 2021;72(2):539-45.

65 Nowotny H, Ahmed SF, Bensing S, Beun JG, Brosamle M, Chifu I, et al. Therapy options for adrenal insufficiency and recommendations for the management of adrenal crisis. Endocrine. 2021;71(3):586-94.

66 Merke DP, Chrousos GP, Eisenhofer G, Weise M, Keil MF, Rogol AD, et al. Adrenomedullary dysplasia and hypofunction in patients with classic 21-hydroxylase deficiency. N Engl J Med. 2000;343(19):1362-8.

67 Charmandari E, Eisenhofer G, Mehlinger SL, Carlson A, Wesley R, Keil MF, et al. Adrenomedullary function may predict phenotype and genotype in classic 21-hydroxylase deficiency. J Clin Endocrinol Metab. 2002;87(7): 3031-7.

68 Keil MF, Bosmans C, Van Ryzin C, Merke DP Hypoglycemia during acute illness in children with classic congenital adrenal hyperplasia. J Pediatr Nurs. 2010;25(1):18-24.

69 Odenwald B, Nennstiel-Ratzel U, Dörr HG, Schmidt H, Wildner M, Bonfig W. Children with classic congenital adrenal hyperplasia experience salt loss and hypoglycemia: evaluation of adrenal crises during the first 6 years of life. Eur J Endocrinol. 2016;174(2):177-86.

70 MacKay D, Nordenström A, Falhammar H. Bilateral adrenalectomy in congenital adrenal hyperplasia: a systematic review and metaanalysis. J Clin Endocrinol Metab. 2018; 103(5):1767-78.

71 Reisch N, Willige M, Kohn D, Schwarz HP, Allolio B, Reincke M, et al. Frequency and causes of adrenal crises over lifetime in patients with 21-hydroxylase deficiency. Eur J Endocrinol. 2012;167(1):35-42.

72 Esteban NV, Loughlin T, Yergey AL, Zawadzki JK, Booth JD, Winterer JC, et al. Daily cortisol production rate in man determined by stable isotope dilution/mass spectrometry. J Clin Endocrinol Metab. 1991;72(1):39-45.

73 Kerrigan JR, Veldhuis JD, Leyo SA, Iranmanesh A, Rogol AD. Estimation of daily cortisol production and clearance rates in normal pubertal males by deconvolution analysis. J Clin Endocrinol Metab. 1993;76(6):1505-10.

74 Purnell JQ, Brandon DD, Isabelle LM, Loriaux DL, Samuels MH. Association of 24-hour cortisol production rates, cortisol-binding globulin, and plasma-free cortisol levels with body composition, leptin levels, and aging in adult men and women. J Clin Endocrinol Metab. 2004;89(1):281-7.

75 Kraan GP, Dullaart RP, Pratt JJ, Wolthers BG, Drayer NM, De Bruin R. The daily cortisol production reinvestigated in healthy men. The serum and urinary cortisol production rates are not significantly different. J Clin Endocrinol Metab. 1998;83(4):1247-52. 
76 Brandon DD, Isabelle LM, Samuels MH, Kendall JW, Loriaux DL. Cortisol production rate measurement by stable isotope dilution using gas chromatography-negative ion chemical ionization mass spectrometry. Steroids. 1999; 64(6):372-8.

77 Choudhury S, Lightman S, Meeran K. Improving glucocorticoid replacement profiles in adrenal insufficiency. Clin Endocrinol. 2019;91(3):367-71.

78 Vargas I, Vgontzas AN, Abelson JL, Faghih RT, Morales KH, Perlis ML. Altered ultradian cortisol rhythmicity as a potential neurobiologic substrate for chronic insomnia. Sleep Med Rev. 2018;41:234-43.

79 Muthusamy K, Elamin MB, Smushkin G, Mu$\operatorname{rad} \mathrm{MH}$, Lampropulos JF, Elamin KB, et al. Clinical review: adult height in patients with congenital adrenal hyperplasia: a systematic review and metaanalysis. J Clin Endocrinol Metab. 2010;95(9):4161-72.

80 Falhammar H, Frisen L, Hirschberg AL, Norrby C, Almqvist C, Nordenskjold A, et al. Increased cardiovascular and metabolic morbidity in patients with 21-hydroxylase deficiency: a Swedish Population-Based National Cohort Study. J Clin Endocrinol Metab. 2015 100(9):3520-8

81 Gomes LG, Mendonca BB, Bachega TASS. Long-term cardio-metabolic outcomes in patients with classical congenital adrenal hyperplasia: is the risk real? Curr Opin Endocrinol Diabetes Obes. 2020;27(3):155-61.

82 Rangaswamaiah S, Gangathimmaiah V, Nordenstrom A, Falhammar H. Bone mineral density in adults with congenital adrenal hyperplasia: a systematic review and meta-analysis. Front Endocrinol. 2020;11:493.

83 Li L, Bensing S, Falhammar H. Rate of fracture in patients with glucocorticoid replacement therapy: a systematic review and metaanalysis. Endocrine. 2021;74(1):29-37.

84 Falhammar H, Frisen L, Hirschberg AL, Nordenskjold A, Almqvist C, Nordenstrom A. Increased prevalence of fractures in congenital adrenal hyperplasia: a Swedish PopulationBased National Cohort Study. J Clin Endocrinol Metab. 2022;107(2):e475-86

85 Nermoen I, Falhammar H. Prevalence and characteristics of adrenal tumors and myelolipomas in congenital adrenal hyperplasia: a systematic review and meta-analysis. Endocr Pract. 2020;26(11):1351-65.

86 Falhammar H, Nyström HF, Ekström U, Granberg S, Wedell A, Thorén M. Fertility, sexuality and testicular adrenal rest tumors in adult males with congenital adrenal hyperplasia. Eur J Endocrinol. 2012;166(3):441-9.

87 Claahsen-van der Grinten HL, Stikkelbroeck N, Falhammar H, Reisch N. Management of endocrine disease: gonadal dysfunction in congenital adrenal hyperplasia. Eur J Endocrinol. 2021;184(3):R85-97.
88 Webb EA, Elliott L, Carlin D, Wilson M, Hall K, Netherton J, et al. Quantitative MRI brain in congenital adrenal hyperplasia: in vivo assessment of the cognitive and structural impact of steroid hormones. J Clin Endocrinol Metab. 2018;103(4):1330-41.

89 Van't Westeinde A, Karlsson L, Thomsen Sandberg M, Nordenström A, Padilla N, Lajic S. Altered gray matter structure and white matter microstructure in patients with congenital adrenal hyperplasia: relevance for working memory performance. Cereb Cortex. 2020;30(5):2777-88.

90 Herting MM, Azad A, Kim R, Tyszka JM, Geffner ME, Kim MS. Brain differences in the prefrontal cortex, amygdala, and hippocampus in youth with congenital adrenal hyperplasia. J Clin Endocrinol Metab. 2020;105(4): 1098-111.

91 Daae E, Feragen KB, Nermoen I, Falhammar H. Psychological adjustment, quality of life, and self-perceptions of reproductive health in males with congenital adrenal hyperplasia: a systematic review. Endocrine. 2018;62(1):313.

92 Nordenskjold A, Holmdahl G, Frisen L, Falhammar H, Filipsson H, Thoren M, et al. Type of mutation and surgical procedure affect long-term quality of life for women with congenital adrenal hyperplasia. J Clin Endocrinol Metab. 2008;93(2):380-6.

93 Falhammar H, Frisen L, Norrby C, Hirschberg AL, Almqvist C, Nordenskjold A, et al. Increased mortality in patients with congenital adrenal hyperplasia due to 21-hydroxylase deficiency. J Clin Endocrinol Metab. 2014; 99(12):E2715-21.

94 Bonfig W, Bechtold S, Schmidt H, Knorr D, Schwarz HP. Reduced final height outcome in congenital adrenal hyperplasia under prednisone treatment: deceleration of growth velocity during puberty. J Clin Endocrinol Metab. 2007;92(5):1635-9.

95 Rivkees SA, Crawford JD. Dexamethasone treatment of virilizing congenital adrenal hyperplasia: the ability to achieve normal growth. Pediatrics. 2000;106(4):767-73.

96 Rivkees SA, Stephenson K. Low-dose dexamethasone therapy from infancy of virilizing congenital adrenal hyperplasia. Int J Pediatr Endocrinol. 2009;2009:274682.

97 Dauber A, Feldman HA, Majzoub JA. Nocturnal dexamethasone versus hydrocortisone for the treatment of children with congenital adrenal hyperplasia. Int J Pediatr Endocrinol. 2010;2010:347636.

98 Whittle E, Falhammar H. Glucocorticoid regimens in the treatment of congenital adrenal hyperplasia: a systematic review and metaanalysis. J Endocr Soc. 2019;3(6):1227-45.

99 Whitaker M, Debono M, Huatan H, Merke D, Arlt W, Ross RJ. An oral multiparticulate, modified-release, hydrocortisone replacement therapy that provides physiological cortisol exposure. Clin Endocrinol. 2014;80(4): 554-61.
100 Stewart PM. Modified-release hydrocortisone: is it time to change clinical practice? J Endocr Soc. 2019;3(6):1150-3.

101 Merke DP, Mallappa A, Arlt W, Brac de la Perriere A, Linden Hirschberg A, Juul A, et al. Modified-release hydrocortisone in congenital adrenal hyperplasia. J Clin Endocrinol Metab. 2021;106(5):e2063-77.

102 Debono M, Ghobadi C, Rostami-Hodjegan A, Huatan H, Campbell MJ, Newell-Price J, et al. Modified-release hydrocortisone to provide circadian cortisol profiles. J Clin Endocrinol Metab. 2009;94(5):1548-54.

103 Quinkler M, Miodini Nilsen R, Zopf K, Ventz M, Øksnes M. Modified-release hydrocortisone decreases BMI and HbAlc in patients with primary and secondary adrenal insufficiency. Eur J Endocrinol. 2015; 172(5):619-26.

104 Giordano R, Guaraldi F, Marinazzo E, Fumarola F, Rampino A, Berardelli R, et al. Improvement of anthropometric and metabolic parameters, and quality of life following treatment with dual-release hydrocortisone in patients with Addison's disease. Endocrine. 2016;51(2):360-8.

105 Isidori AM, Venneri MA, Graziadio C, Simeoli C, Fiore D, Hasenmajer V, et al. Effect of once-daily, modified-release hydrocortisone versus standard glucocorticoid therapy on metabolism and innate immunity in patients with adrenal insufficiency (DREAM): a single-blind, randomised controlled trial. Lancet Diabetes Endocrinol. 2018;6(3):173-85.

106 Venneri MA, Hasenmajer V, Fiore D, Sbardella E, Pofi R, Graziadio C, et al. Circadian rhythm of glucocorticoid administration entrains clock genes in immune cells: a DREAM Trial Ancillary Study. J Clin Endocrinol Metab. 2018;103(8):2998-3009.

107 Nilsson AG, Bergthorsdottir R, Burman P, Dahlqvist P, Ekman B, Engstrom BE, et al. Long-term safety of once-daily, dual-release hydrocortisone in patients with adrenal insufficiency: a phase $3 \mathrm{~b}$, open-label, extension study. Eur J Endocrinol. 2017;176(6): 715-25.

108 Krekeler C, Kropp P, Blacha AK, Rahvar AH, Harbeck B. Dual-release hydrocortisone and its benefits on cognitive function and quality of sleep. Endocrine. 2021;72(1) 223-33.

109 Boesen VB, Borresen SW, Christoffersen T, Klose M, Watt T, Feldt-Rasmussen U. The effect of dual-release versus conventional hydrocortisone on fatigue, measured by ecological momentary assessments. Endocrine. 2021;71(2):467-75.

110 Park J, Das U, Didi M, Ramakrishnan R, Peak M, Newland P, et al. The challenges of cortisol replacement therapy in childhood: observations from a case series of children treated with modified-release hydrocortisone. Paediatr Drugs. 2018;20(6):567-73. 
111 Verma S, Vanryzin C, Sinaii N, Kim MS, Nieman LK, Ravindran S, et al. A pharmacokinetic and pharmacodynamic study of delayed- and extended-release hydrocortisone (Chronocort) vs. conventional hydrocortisone (Cortef) in the treatment of congenital adrenal hyperplasia. Clin Endocrinol. 2010; 72(4):441-7.

112 Mallappa A, Sinaii N, Kumar P, Whitaker MJ, Daley LA, Digweed D, et al. A phase 2 study of Chronocort, a modified-release formulation of hydrocortisone, in the treatment of adults with classic congenital adrenal hyperplasia. J Clin Endocrinol Metab. 2015;100(3):1137-45.

113 Jones CM, Mallappa A, Reisch N, Nikolaou N, Krone N, Hughes BA, et al. Modified-release and conventional glucocorticoids and diurnal androgen excretion in congenital adrenal hyperplasia. J Clin Endocrinol Metab. 2017;102(6):1797-806.

114 Nella AA, Mallappa A, Perritt AF, Gounden V, Kumar P, Sinaii N, et al. A phase 2 study of continuous subcutaneous hydrocortisone infusion in adults with congenital adrenal hyperplasia. J Clin Endocrinol Metab. 2016; 101(12):4690-8
115 Bryan SM, Honour JW, Hindmarsh PC. Management of altered hydrocortisone pharmacokinetics in a boy with congenital adrenal hyperplasia using a continuous subcutaneous hydrocortisone infusion. J Clin Endocrinol Metab. 2009;94(9):3477-80.

116 Hindmarsh PC. The child with difficult to control congenital adrenal hyperplasia: is there a place for continuous subcutaneous hydrocortisone therapy. Clin Endocrinol. 2014;81(1):15-8.

117 Rogers MA, Liu J, Song BL, Li BL, Chang CC, Chang TY. Acyl-CoA:cholesterol acyltransferases (ACATs/SOATs): Enzymes with multiple sterols as substrates and as activators. J Steroid Biochem Mol Biol. 2015;151: 102-7.

118 LaPensee CR, Mann JE, Rainey WE, Crudo V, Hunt SW 3rd, Hammer GD. ATR-101, a selective and potent inhibitor of acyl-coa acyltransferase 1, induces apoptosis in h295r adrenocortical cells and in the adrenal cortex of dogs. Endocrinology. 2016;157(5):177588 .
119 El-Maouche D, Merke DP, Vogiatzi MG, Chang AY, Turcu AF, Joyal EG, et al. A phase 2, multicenter study of nevanimibe for the treatment of congenital adrenal hyperplasia. J Clin Endocrinol Metab. 2020; 105(8):2771-8.

120 Auchus RJ, Buschur EO, Chang AY, Hammer GD, Ramm C, Madrigal D, et al. Abiraterone acetate to lower androgens in women with classic 21-hydroxylase deficiency. J Clin Endocrinol Metab. 2014;99(8):276370 .

121 Wright C, O’Day P, Alyamani M, Sharifi N, Auchus RJ. Abiraterone acetate treatment lowers 11-oxygenated androgens. Eur J Endocrinol. 2020;182(4):413-21.

122 Turcu AF, Spencer-Segal JL, Farber RH, Luo $\mathrm{R}$, Grigoriadis DE, Ramm CA, et al. Singledose study of a corticotropin-releasing factor receptor-1 antagonist in women with 21-hydroxylase deficiency. J Clin Endocrinol Metab. 2016;101(3):1174-80.

123 Sarafoglou K, Barnes CN, Huang M, Imel EA, Madu IJ, Merke DP, et al. Tildacerfont in adults with classic congenital adrenal hyperplasia: results from two phase 2 studies. J Clin Endocrinol Metab. 2021;106(11): e4666-79. 